\title{
Effective Constipation Treatment Changes More Than Bowel Frequency: A Systematic Review and Meta-Analysis
}

\author{
Klaus Bielefeldt, ${ }^{1 *}$ David J Levinthal, ${ }^{1}$ and Salman Nusrat ${ }^{2}$ \\ ${ }^{\prime}$ University of Pittsburgh Medical Center, Pittsburgh, PA, USA; and ${ }^{2}$ University of Oklahoma Health Sciences Center, Oklahoma, OK, USA
}

\begin{abstract}
Background/Aims
The marketing of newer agents for treatment of constipation and irritable bowel syndrome with constipation (IBS-C) emphasize improvements in abdominal pain. However, it is not clear whether this observation reflects a unique visceral analgesic effect of these agents or is a general feature of effective laxation. We sought to determine the relationship between improvements in bowel frequency and decreases in abdominal pain in clinical trials of patients with constipation or IBS-C.
\end{abstract}

\section{Methods}

We searched "PubMed" and "Embase" databanks for clinical trials in patients with constipation or IBS-C, targeting publications that provided detailed data on bowel movement frequency and pain intensity before and after an intervention. We abstracted the results and performed meta-analytic and meta-regression analyses.

\section{Results}

Twenty-seven trials (16 constipation and $11 \mathrm{IBS}$ ) met entry criteria. Baseline weekly bowel movement frequency was low with 2.35 (2.07-2.64) with differences between constipation (2.00 [1.62-2.38]) and IBS-C (2.77 [2.40-3.14]; $Q=8.18 ; P=0.002)$. Studies reported moderate pain levels (2.12 [1.81-2.42]) with comparable baseline levels in constipation (2.02 [1.63-2.42]) and IBS-C (2.35 $[2.10-2.60] ; \mathrm{Q}=1.92 ; P=0.167)$. Treatments increased bowel frequency by $2.17[1.88-2.47]$ and lowered pain ratings by 0.58 [0.49-0.68]. Meta-regression demonstrated a significant correlation between treatment-induced increases in bowel frequency and decreased pain ratings.

\section{Conclusions}

Our analysis suggests that reduction of abdominal pain observed in clinical trials of constipation and IBS-C is associated with laxation, and may not require specific drug mechanisms, thus arguing against a unique advantage of newer agents over traditional laxatives in the treatment of constipation and IBS-C.

\section{(J Neurogastroenterol Motil 2016;22:31-45)}

\section{Key Words}

Abdominal pain; Constipation; Irritable bowel syndrome; Laxatives

Received: October 21, 2015 Revised: November 20, 2015 Accepted: December 3, 2015

(a) This is an Open Access article distributed under the terms of the Creative Commons Attribution Non-Commercial License (http://creativecommons. org/licenses/by-nc/4.0) which permits unrestricted non-commercial use, distribution, and reproduction in any medium, provided the original work is properly cited.

${ }^{*}$ Correspondence: Klaus Bielefeldt, MD, PhD

University of Pittsburgh Medical Center, Division of Gastroenterology, 200 Lothrop St., Pittsburgh, PA 15217, USA

Tel: +1-412-864-7087, Fax: +1-412-383-6731, E-mail: bielefeldtk@upmc.edu 


\section{Introduction}

Constipation is a common problem that is often associated with other symptoms, including painful defecation, bloating, and abdominal pain. ${ }^{1}$ Although current consensus criteria emphasize the distinction between functional constipation and constipationpredominant irritable bowel syndrome (IBS-C), ${ }^{2}$ systematic evaluations have shown a substantial overlap between these disorders. ${ }^{1,3,4}$ Thus, it is not surprising that the treatment approaches for either disorders overlap as well. After serious adverse events led to the withdrawal of several drugs targeting functional gastrointestinal diseases, ${ }^{5-7}$ regulatory agencies in the United States have put forth more stringent criteria for the approval and post-marketing surveillance of novel medications. ${ }^{8}$ As a consequence, recent clinical trials have focused on patient-reported outcomes and the perceived adequacy of responses, such as the subjective satisfaction with bowel movements and detailed pain ratings. Considering the defining role of pain and discomfort in IBS-C, a paradigm is evolving, which first examines efficacy in patients with chronic constipation, followed by trials in patients with IBS-C, which require more comprehensive assessments that demonstrate improvement beyond changes in bowel patterns. ${ }^{9-13}$ The results of the newer studies demonstrated lower pain ratings during treatment and prompted speculations about specific analgesic effects of these agents, potentially differentiating them from more conventional laxatives, a feature that has been particularly highlighted in reviews and advertising campaigns. ${ }^{14,15}$ Based largely on their impact on abdominal pain, the recently introduced pro-secretory agents (lubiprostone and linaclotide) were approved in the United States not only for the treatment of chronic constipation, but also specifically for the management of IBS-C, with marketing campaigns emphasizing their presumably unique benefits related to pain relief. ${ }^{16-18}$ In the case of linaclotide, preclinical mechanistic studies supported the clinical data and suggested a possible specific analgesic effect. These investigations, which were previously also conducted with tegaserod, assessed acute responses to colorectal distension or stretch in normal subjects or animals. ${ }^{19-21}$
Similar experiments did not reveal effects on sensory function with lubiprostone. ${ }^{22}$ Despite the different impact on colorectal sensatory mechanisms, ${ }^{19,21-23}$ linaclotide, lubiprostone and tegaserod alleviated chronic pain ratings in IBS-C and constipation. 9-11,24-26

Interestingly, two studies compared the effects of tegaserod with polyethylene glycol (PEG), which acts as an osmotic laxative and should thus not directly affect sensory mechanisms or pain. However, the simple laxative was either superior to or demonstrated an equivalent effect to tegaserod. ${ }^{27,28}$ In addition, reducing bowel frequency in healthy volunteers with loperamide led to symptoms consistent with IBS-C. ${ }^{29}$ These studies suggest that constipation is not exclusively defined by a low bowel frequency and/or the need for excessive straining due to hard bowel movements. Improving constipation may therefore also improve associated symptoms, such as discomfort and pain. Considering this potential association between constipation and abdominal discomfort, we hypothesized that pain relief should correlate with the laxative effects of these agents as a general phenomenon and may be largely independent of the specific mechanism of action of the agent. Thus, we performed a systematic review of clinical trials that included detailed assessments of both bowel patterns and abdominal discomfort in adults suffering from chronic constipation or IBS-C. This approach allowed us to use a meta-regression analysis to determine the relationship between these 2 clinical variables.

\section{Materials and Methods}

\section{Search Strategy}

We searched the "PubMed" and "Embase" databases for publications between 1974 and October 2014 using the terms "constipation" and "pain," along with filter settings for "clinical trials," "humans," and articles published in "English." For our "Embase" search, we also further restricted the search to "fully published" articles. All of the retrieved titles were independently reviewed to determine whether the focus was on treatment of chronic constipation or IBS-C in adults, and whether original data were presented.

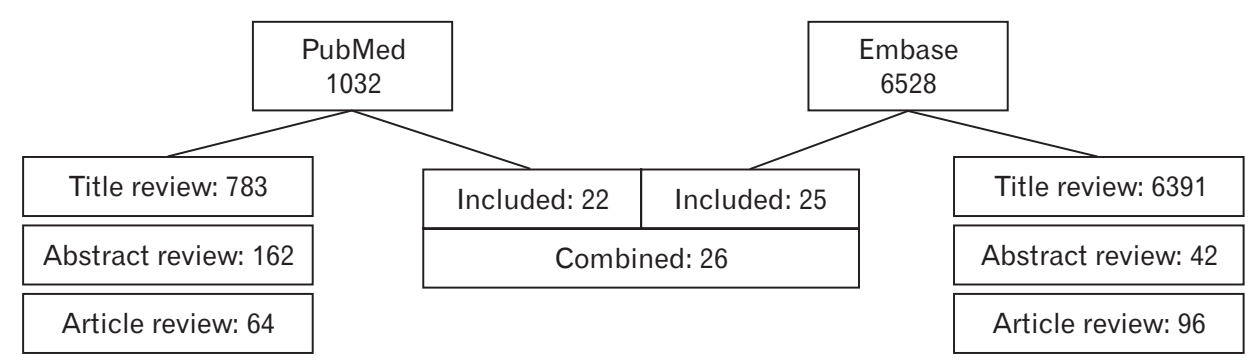

Figure 1. Flow chart documenting the results of our search strategy. 
Titles meeting these criteria were then included in the next level of review with an examination of abstracts to assess study design, clinical variables measured, and target population. Finally, we retrieved and reviewed full-length articles that potentially met inclusion criteria based on the information presented in the abstract. Two of the authors (K.B. and S.N.) conducted the review independently, and reconciled discrepancies by involving a third reviewer (D.J.L.).

\section{Data Abstraction and Inclusion Criteria}

We recorded trial design and analytic approach, abstracting data based on the "intention to treat" rather than "per protocol" analyses if both were provided. We abstracted data including sample size, type of investigational and control interventions, treatment allocation, dropout rates, and trial duration (only studies measuring a treatment for 4 weeks or more were included). Considering our underlying hypothesis, we recorded both baseline assessments of bowel movement frequency and abdominal pain intensity scores, and the results at the conclusion of the active treatment phase of the trial. If more than one measure of bowel patterns was provided, we selected the number of weekly defecations. If treatment-induced

Table 1. Studies Included in the Analysis

\begin{tabular}{|c|c|c|c|c|c|c|c|c|}
\hline Sample (n) & Design & Intervention & Allocation & Analysis & Drop-out & Endpoints & $\begin{array}{l}\text { Duration } \\
\text { (weeks) }\end{array}$ & Reference \\
\hline \multicolumn{9}{|l|}{ Constipation } \\
\hline 22 & $\mathrm{COD}$ & $\begin{array}{l}\text { Bran } \\
\text { Placebo }\end{array}$ & NA & ITT & & $\begin{array}{l}\mathrm{BM} / \mathrm{W} \\
\text { NRS 0-3 }\end{array}$ & 4 & 32 \\
\hline 237 & $\mathrm{RCT}$ & $\begin{array}{l}\text { Lubiprostone } \\
\text { Placebo }\end{array}$ & $1: 1$ & ITT & $\begin{array}{l}\text { A: } 20 \\
\text { C: } 10\end{array}$ & $\begin{array}{l}\mathrm{SBM} / \mathrm{W} \\
\text { NRS 0-4 }\end{array}$ & 4 & 24 \\
\hline $\begin{array}{l}130 \\
137\end{array}$ & $\mathrm{RCT}$ & $\begin{array}{l}\text { PEG \& Electrolytes } \\
\text { PEG }\end{array}$ & $1: 1$ & ITT & $\begin{array}{l}\text { A: } 30 \\
C: 25\end{array}$ & $\begin{array}{l}\mathrm{BM} / \mathrm{W} \\
\text { NRS 1-4 }\end{array}$ & 4 & 33 \\
\hline 120 & $\mathrm{RCT}$ & $\begin{array}{l}\text { Hemp } \\
\text { Placebo }\end{array}$ & $1: 1$ & ITT & $\begin{array}{l}\text { A: } 18 \\
\text { C: } 13\end{array}$ & $\begin{array}{l}\mathrm{BM} / \mathrm{W} \\
\text { NRS 0-6 }\end{array}$ & 8 & 34 \\
\hline 109 & Cohort & $\begin{array}{l}\text { Biofeedback } \\
\text { Laxatives }\end{array}$ & $\begin{array}{l}\text { A: } 55 \\
\text { C: } 54\end{array}$ & NA & NA & $\begin{array}{l}\mathrm{BM} / \mathrm{W} \\
\text { NRS 0-4 }\end{array}$ & 51 & 35 \\
\hline 66 & $\mathrm{RCT}$ & $\begin{array}{l}\text { Probiotic } \\
\text { Placebo }\end{array}$ & $1: 1$ & ITT & $\begin{array}{l}\text { A: } 2 \\
\text { C: } 4\end{array}$ & $\begin{array}{l}\mathrm{SBM} / \mathrm{W} \\
\text { NRS 0-4 }\end{array}$ & 4 & 36 \\
\hline 242 & $\mathrm{RCT}$ & $\begin{array}{l}\text { Lubiprostone } \\
\text { Placebo }\end{array}$ & $1: 1$ & ITT & $\begin{array}{l}\text { A: } 9 \\
\text { C: } 5\end{array}$ & $\begin{array}{l}\mathrm{SBM} / \mathrm{W} \\
\text { NRS 0-4 }\end{array}$ & 4 & 11 \\
\hline 1348 & $\mathrm{RCT}$ & $\begin{array}{l}\text { Tegaserod (2 dosages) } \\
\text { Placebo }\end{array}$ & $1: 1: 1$ & ITT & $\begin{array}{r}\text { A: } 77 \\
67 \\
\text { C: } 86\end{array}$ & $\begin{array}{l}\mathrm{SBM} / \mathrm{W} \\
\text { NRS 0-4 }\end{array}$ & 12 & 25 \\
\hline 1264 & $\mathrm{RCT}$ & $\begin{array}{l}\text { Tegaserod (2 dosages) } \\
\text { Placebo }\end{array}$ & $1: 1: 1$ & ITT & $\begin{array}{r}\text { A: } 72 \\
70 \\
\text { C: } 74\end{array}$ & $\begin{array}{l}\mathrm{SBM} / \mathrm{W} \\
\text { NRS } 0-4\end{array}$ & 12 & 26 \\
\hline 45 & Cohort & Sacral Stimulator & NA & $\mathrm{NA}$ & & $\begin{array}{l}\mathrm{SBM} / \mathrm{W} \\
\mathrm{VAS}\end{array}$ & 4 & 37 \\
\hline 16 & $\mathrm{COD}$ & $\begin{array}{l}\text { Colchicine } \\
\text { Placebo }\end{array}$ & $\mathrm{NA}$ & ITT & & $\begin{array}{l}\mathrm{BM} / \mathrm{W} \\
\mathrm{VAS}\end{array}$ & 4 & 40 \\
\hline 7 & Cohort & Colchicine & NA & $\mathrm{NA}$ & & $\begin{array}{l}\mathrm{SBM} / \mathrm{W} \\
\mathrm{NRS} 0-10\end{array}$ & 4 & 38 \\
\hline 13 & Cohort & Colectomy & $\mathrm{NA}$ & $\mathrm{NA}$ & & $\begin{array}{l}\mathrm{SBM} / \mathrm{W} \\
\text { NRS } 0-10\end{array}$ & NA & 39 \\
\hline 82 & $\mathrm{RCT}$ & $\begin{array}{l}\text { Cisapride } \\
\text { Placebo }\end{array}$ & $1: 1$ & ITT & $\begin{array}{l}\text { A: } 6 \\
\text { C: } 6\end{array}$ & $\begin{array}{l}\mathrm{CSBM} / \mathrm{W} \\
\text { VAS }\end{array}$ & 12 & 41 \\
\hline 32 & $\mathrm{RCT}$ & $\begin{array}{l}\text { Mosparide } \\
\text { Domperidone }\end{array}$ & Unclear & $\mathrm{PP}$ & $\begin{array}{l}20 \\
12\end{array}$ & $\begin{array}{l}\mathrm{BM} / \mathrm{w} \\
\mathrm{NRS} 0-6\end{array}$ & 8 & 53 \\
\hline 43 & $\mathrm{OL}$ & $\mathrm{Na}$ Phosphate (2 dosages) & Unclear & $\mathrm{PP}$ & $\begin{array}{l}18 \\
25\end{array}$ & $\begin{array}{l}\mathrm{BM} / \mathrm{W} \\
\mathrm{NRS}(0-4)\end{array}$ & 4 & 52 \\
\hline
\end{tabular}


Table 1. Continued

\begin{tabular}{|c|c|c|c|c|c|c|c|c|}
\hline Sample (n) & Design & Intervention & Allocation & Analysis & Drop-out & Endpoints & $\begin{array}{l}\text { Duration } \\
\text { (weeks) }\end{array}$ & Reference \\
\hline \multicolumn{9}{|l|}{ IBS } \\
\hline 34 & $\mathrm{RCT}$ & $\begin{array}{l}\text { Probiotic } \\
\text { Placebo }\end{array}$ & $1: 1$ & ITT & & $\begin{array}{l}\mathrm{BM} / \mathrm{W} \\
\mathrm{NRS} 1-6\end{array}$ & 4 & 44 \\
\hline 42 & $\mathrm{RCT}$ & $\begin{array}{l}\text { PEG } \\
\text { Placebo }\end{array}$ & $1: 1$ & ITT & & $\begin{array}{l}\mathrm{BM} / \mathrm{W} \\
\mathrm{VAS}\end{array}$ & 4 & 45 \\
\hline 139 & $\mathrm{RCT}$ & $\begin{array}{l}\text { PEG } \\
\text { Placebo }\end{array}$ & $1: 1$ & ITT & $\begin{array}{l}\text { A: } 7 \\
\text { C: } 8\end{array}$ & $\begin{array}{l}\text { SBM/W } \\
\text { NRS 0-4 }\end{array}$ & 4 & 46 \\
\hline 22 & $\mathrm{RCT}$ & $\begin{array}{l}\text { Tegaserod } \\
\text { PEG }\end{array}$ & $1: 1$ & ITT & & $\begin{array}{l}\mathrm{BM} / \mathrm{W} \\
\text { NRS 0-3 }\end{array}$ & 4 & 27 \\
\hline 193 & $\mathrm{RCT}$ & Lubiprostone (3 dosages) & $1: 1: 1: 1$ & ITT & $\begin{aligned} & \text { A: } 10 \\
& 16 \\
& 15 \\
& \text { C: } 7\end{aligned}$ & $\begin{array}{l}\mathrm{SBM} / \mathrm{W} \\
\text { NRS 0-4 }\end{array}$ & 12 & 12 \\
\hline 803 & $\mathrm{RCT}$ & $\begin{array}{l}\text { Linaclotide } \\
\text { Placebo }\end{array}$ & $1: 1$ & ITT & $\begin{array}{l}\text { A: } 94 \\
\text { C: } 62\end{array}$ & $\begin{array}{l}\mathrm{SBM} / \mathrm{W} \\
\text { NSR } 0-10\end{array}$ & 12 & 47 \\
\hline 179 & $\mathrm{RCT}$ & $\begin{array}{l}\text { Probiotic } \\
\text { Placebo }\end{array}$ & $1: 1$ & ITT & & $\begin{array}{l}\mathrm{SBM} / \mathrm{W} \\
\text { NRS 0-5 }\end{array}$ & 4 & 48 \\
\hline 41 & $\mathrm{RCT}$ & $\begin{array}{l}\text { Probiotic } \\
\text { Placebo }\end{array}$ & Unclear & ITT & $\begin{array}{l}\text { A: } 19 \\
C: 22\end{array}$ & $\begin{array}{l}\mathrm{BM} / \mathrm{W} \\
\mathrm{VAS}\end{array}$ & 12 & 43 \\
\hline 212 & $\mathrm{OL}$ & Tegaserod & & PP & & $\begin{array}{l}\mathrm{BM} / \mathrm{W} \\
\text { NRS 0-4 }\end{array}$ & 12 & 51 \\
\hline 90 & $\mathrm{RCT}$ & $\begin{array}{l}\text { Herbals } \\
\text { Placebo }\end{array}$ & $1: 1$ & ITT & & $\begin{array}{l}\mathrm{BM} / \mathrm{W} \\
\mathrm{NRS} 1-3\end{array}$ & 12 & 49 \\
\hline 69 & $\mathrm{RCT}$ & $\begin{array}{l}\text { Cisapride } \\
\text { Placebo }\end{array}$ & $1: 1$ & ITT & $\begin{array}{l}\text { A: } 4 \\
\text { C: } 5\end{array}$ & $\begin{array}{l}\mathrm{BM} / \mathrm{W} \\
\text { NRS 0-3 }\end{array}$ & 12 & 50 \\
\hline
\end{tabular}

COD, cross over design; NA, not applicable; ITT, intention to treat; BM/W, bowel movements per week; NRS, numeric rating scale (given with range); RCT, randomized controlled trial; A, active therapy; SBM/W, spontaneous bowel movements per week; C, control group; PEG, polyethylene glycol; CSBM/W, complete spontaneous bowel movements per week; VAS, visual analog scale; OL, open label trial; PP, per protocol; IBS, irritable bowel syndrome.

The endpoints are given for bowel frequency (top) and pain intensity (bottom).

changes in bowel patterns were not described in sufficient detail, we then considered dichotomized response rates based on predefined changes in bowel patterns as a secondary endpoint. Only patientbased ratings and reports were used.

\section{Exclusion Criteria}

Studies performed with children, patient cohorts with a disease duration of less than 3 months, patients with opioid-induced constipation, results describing only global ratings without specific information about bowel frequency or pain intensity, articles providing data expressed only as a median and/or range, and post-hoc analyses describing subgroups or treatment with open-label extensions of previously published trials were excluded.

\section{Analytic Strategy}

We summarized bowel frequency as defecations per week and pain intensity ratings as key variables at baseline, and also determined treatment-induced changes at the end of the predefined trial duration. As reports relied on different scales, we abstracted the ratings of pain intensity, and normalized the mean and variance to a 5-point scale. We assessed these data for cohorts with constipation and/or IBS-C, and used the more conservative random effects meta-regression of the published data to determine if changes in bowel movement frequency predicted changes in pain intensity as the dependent outcome measure. ${ }^{30}$ Considering the underlying hypothesis, we separately recorded effects of active treatments and placebo or sham controls, but did not compare the efficacy of these different treatments on key endpoints. As opposed to such a metaanalytic approach that assesses the differential impact of treatments on outcomes between groups or at distinct time points, we employed meta-regression techniques that correlate changes in a pre-defined covariate with the outcome of interest. ${ }^{31}$ While such an approach is 
Table 2. Studies with Dichotomized Endpoints Related to Bowel Patterns

\begin{tabular}{|c|c|c|c|c|c|c|c|c|}
\hline Sample (n) & Design & Intervention & Allocation & Analysis & Drop-out & Endpoints & $\begin{array}{l}\text { Duration } \\
\text { (weeks) }\end{array}$ & Reference \\
\hline \multicolumn{9}{|l|}{ Constipation } \\
\hline \multirow[t]{2}{*}{713} & $\mathrm{RCT}$ & Prucalopride (2 dosages) & $1: 1: 1$ & ITT & $\begin{array}{r}\text { A } 29 \\
54\end{array}$ & $\begin{array}{l}\geq 3 \mathrm{CSBM} / \mathrm{W} \\
\mathrm{PAC}-\mathrm{Sym}\end{array}$ & 12 & 64 \\
\hline & & Placebo & & & C 33 & & & \\
\hline \multirow[t]{2}{*}{1272} & $\mathrm{RCT}$ & Linaclotide (2 trials, 2 dosages) & $1: 1: 1$ & ITT & $\begin{array}{r}\text { A } 71 \\
76\end{array}$ & $\begin{array}{l}\geq 3 \mathrm{CSBM} / \mathrm{W} \\
\operatorname{NRS}(0-5)\end{array}$ & 12 & 80 \\
\hline & & Placebo & & & C 56 & & & \\
\hline \multirow[t]{2}{*}{307} & $\mathrm{RCT}$ & Linaclotide (4 dosages) & $4: 1$ & ITT & $\begin{array}{c}\text { A } 5 \\
\quad 6 \\
4 \\
\\
12\end{array}$ & $\begin{array}{l}\geq 3 \mathrm{CSBM} / \mathrm{W} \\
\operatorname{NRS}(0-5)\end{array}$ & 4 & 9 \\
\hline & & Placebo & & & C 8 & & & \\
\hline \multirow[t]{2}{*}{620} & RCT & Prucalopride (2 dosages) & $1: 1: 1$ & ITT & $\begin{array}{r}\text { A } 27 \\
31\end{array}$ & $\begin{array}{l}\geq 3 \mathrm{CSBM} / \mathrm{W} \\
\text { PAC-Sym }\end{array}$ & 12 & 63 \\
\hline & & Placebo & & & C 23 & & & \\
\hline \multirow[t]{2}{*}{641} & RCT & Prucalopride (2 dosages) & $1: 1: 1$ & ITT & $\begin{array}{r}\text { A } 20 \\
24\end{array}$ & $\begin{array}{l}\geq 3 \mathrm{CSBM} / \mathrm{W} \\
\mathrm{PAC}-\mathrm{Sym}\end{array}$ & 12 & 65 \\
\hline & & Placebo & & & C 30 & & & \\
\hline 501 & RCT & $\begin{array}{l}\text { Prucalopride } \\
\text { Placebo }\end{array}$ & $1: 1$ & ITT & $\begin{array}{l}\text { A } 23 \\
\text { C } 18\end{array}$ & $\begin{array}{l}\geq 3 \mathrm{CSBM} / \mathrm{W} \\
\text { PAC-Sym }\end{array}$ & 12 & 81 \\
\hline 322 & $\mathrm{RCT}$ & $\begin{array}{l}\text { Tegaserod } \\
\text { Placebo }\end{array}$ & $1: 1$ & ITT & $\begin{array}{l}\text { A } 28 \\
\text { P } 25\end{array}$ & $\begin{array}{l}\text { Increase of } \geq 1 \\
\mathrm{CSBM} / \mathrm{W} \\
\operatorname{NRS}(0-4)\end{array}$ & 12 & 82 \\
\hline 70 & RCT & $\begin{array}{l}\text { PEG } \\
\text { Placebo }\end{array}$ & $1: 1$ & ITT & $\begin{array}{l}\text { A } 10 \\
\text { P } 4\end{array}$ & $\begin{array}{l}\mathrm{BM} / \mathrm{W} \\
\mathrm{NRS}(0-4)\end{array}$ & 20 & 83 \\
\hline 237 & $\mathrm{RCT}$ & $\begin{array}{l}\text { PEG } \\
\text { Tegaserod }\end{array}$ & $1: 1$ & ITT & $\begin{array}{l}\text { A } 14 \\
\text { A } 20\end{array}$ & $\begin{array}{l}\mathrm{BM} / \mathrm{W} \\
\mathrm{PAC}-\mathrm{Sym}\end{array}$ & 12 & 28 \\
\hline \multicolumn{9}{|l|}{ IBS } \\
\hline 804 & RCT & $\begin{array}{l}\text { Linaclotide } \\
\text { Placebo }\end{array}$ & $1: 1$ & ITT & $\begin{array}{l}\text { A } 108 \\
\text { C } 98\end{array}$ & $\geq 3 \mathrm{CSBM} / \mathrm{W}$ & 12 & 67 \\
\hline 419 & RCT & Linaclotide (4 dosages) & $4: 1$ & ITT & $\begin{array}{r}\text { A } 16 \\
15 \\
14 \\
18\end{array}$ & $\begin{array}{l}\geq 3 \mathrm{CSBM} / \mathrm{W} \\
\text { (75\% of the time) } \\
\operatorname{NRS}(0-5)\end{array}$ & 12 & 10 \\
\hline 1154 & $\mathrm{RCT}$ & $\begin{array}{l}\text { Placebo } \\
\text { Lubiprostone } \\
\text { Placebo }\end{array}$ & $2: 1$ & ITT & $\begin{array}{l}\text { C } 20 \\
\text { A } 183 \\
\text { P } 99\end{array}$ & $\begin{array}{l}\mathrm{SBM} / \mathrm{W} \\
\mathrm{NRS}(0-4)\end{array}$ & 12 & 77 \\
\hline 1519 & $\mathrm{RCT}$ & $\begin{array}{l}\text { Tegaserod } \\
\text { Placebo }\end{array}$ & $1: 1$ & ITT & $\begin{array}{l}\text { A } 158 \\
\text { P } 161\end{array}$ & $\begin{array}{l}\mathrm{BM} / \mathrm{W} \\
\mathrm{NRS}(0-4)\end{array}$ & 12 & 84 \\
\hline
\end{tabular}

RCT, randomized controlled trial; ITT, intention to treat; A, active therapy; CSBM/W, complete spontaneous bowel movements per week; C, control group; PACSym, Patient Assessment of Constipation Symptoms; NRS, numeric rating scale (given with range); PEG, polyethylene glycol; BM/W, bowel movements per week; IBS, irritable bowel syndrome; SBM/W, spontaneous bowel movements per week.

The endpoints are given for bowel frequency (top) and change in pain intensity (bottom).

similar to conventional regression analyses, meta-regression does not correlate individual data points, but uses aggregate data, which require appropriate measures of variance to limit errors associated with this approach (see exclusion criteria). Unless indicated otherwise, data are given as mean with $95 \%$ confidence interval. 


\section{Results}

Using our initial search strategy, the "PubMed" search yielded 3737 publications, which dropped to 1032 when the predefined filter settings were applied (Fig. 1). We then excluded 783 publications because the description given in the title clearly did not meet inclusion criteria. An additional 163 publications were rejected based on a review of abstracts. The remaining 87 articles were then reviewed in greater detail for potential inclusion. Of this number, 64 publications were not included in the analysis, primarily due to missing details on abdominal pain or bowel patterns, leaving a total of 23 studies.

The initial "Embase" search identified 6528 publications, with 6391 articles excluded based upon further filtering and review of the titles. An additional 42 publications were excluded based on a

\section{A}

\section{Reference}

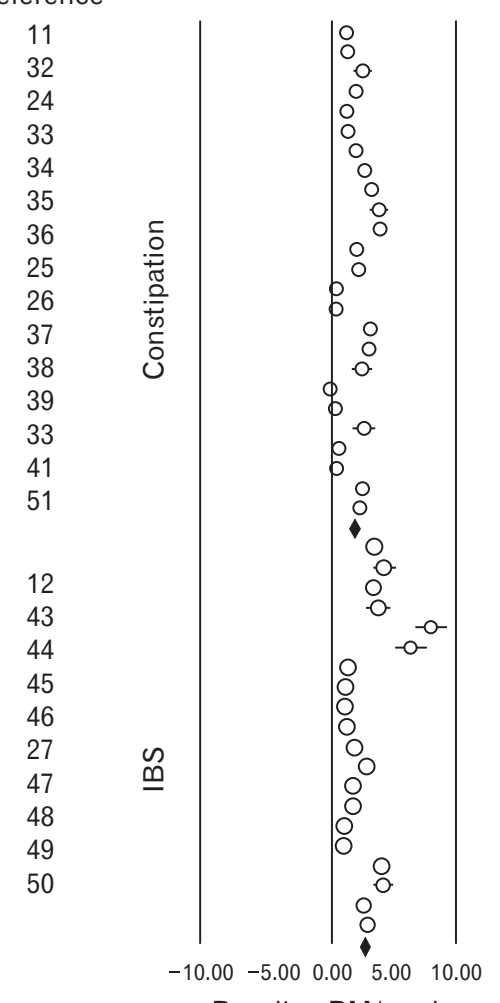

Baseline BM/week

\section{C}

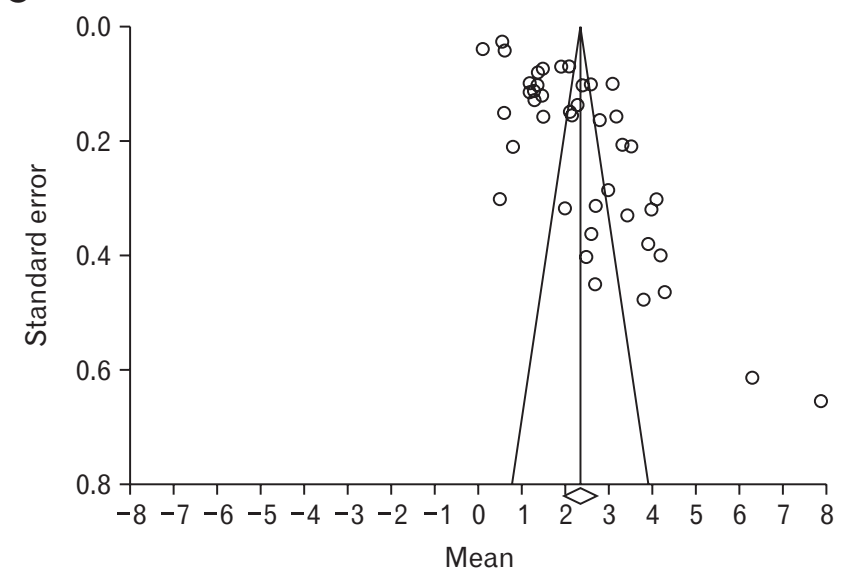

\section{B}

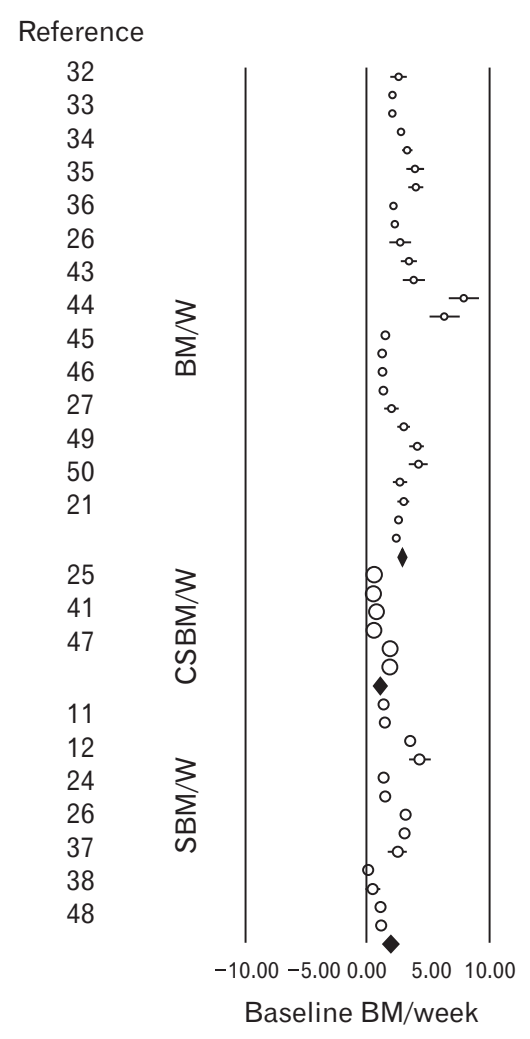

Figure 2. Forest plot showing weekly bowel frequencies reported for the different cohorts included in this analysis. (A) The data are grouped based on the underlying diagnosis, with the circled symbols showing the mean results with 95\% confidence interval. (B) Separates findings based on the endpoint chosen. (C) Shows the funnel plot for baseline bowel frequencies. Study data include results for active treatment and placebo. IBS, irritable bowel syndrome; SBM/ $\mathrm{W}$, spontaneous bowel movements per week; CSBM/W, complete spontaneous bowel movements per week; BM/W, bowel movements per week. 
review of the abstracts. These articles included all but one of the previously identified publications from the "PubMed" search, and 4 additional studies (Table 1). The main exclusion criteria were insufficient details about bowel patterns or pain ratings, short trial duration, or a focus on pediatric patients (Fig. 1). In addition to the publications described above, 13 studies used a predefined threshold for treatment response to dichotomize the data and report

A

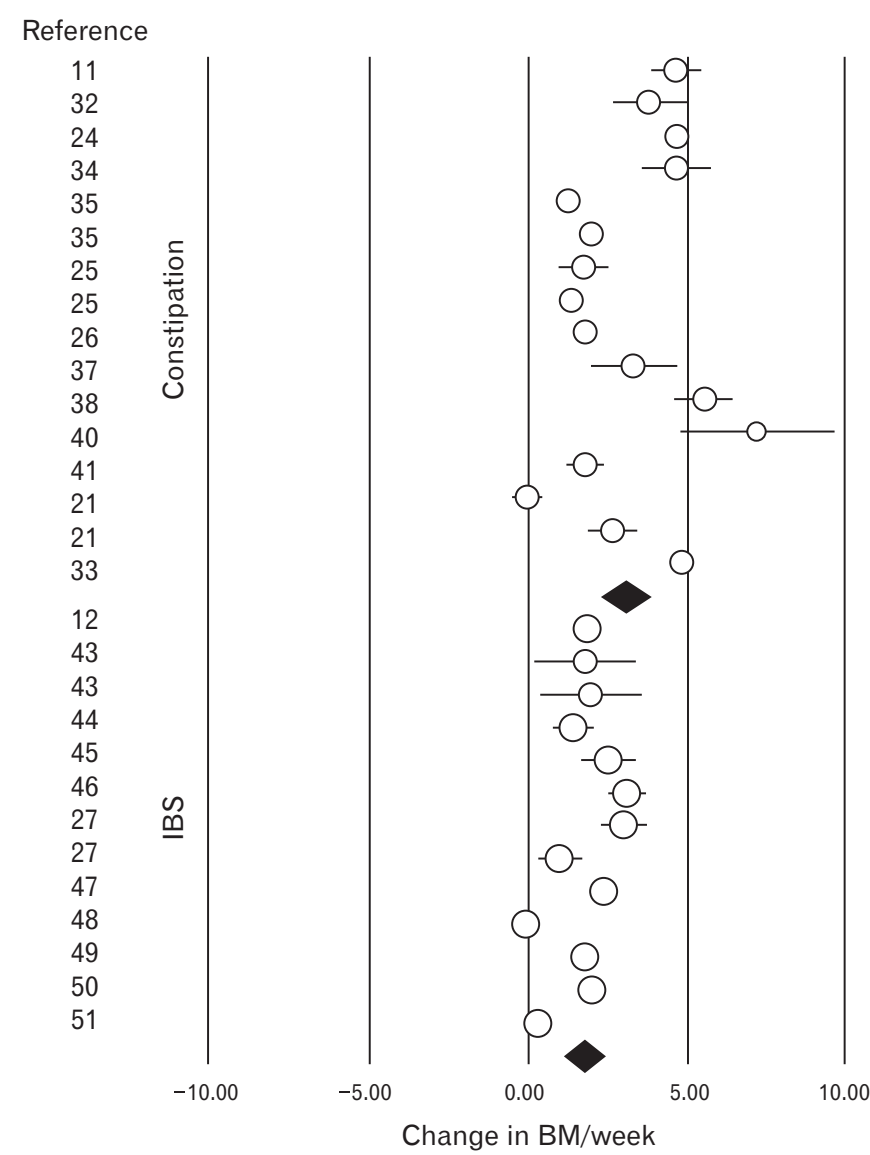

C

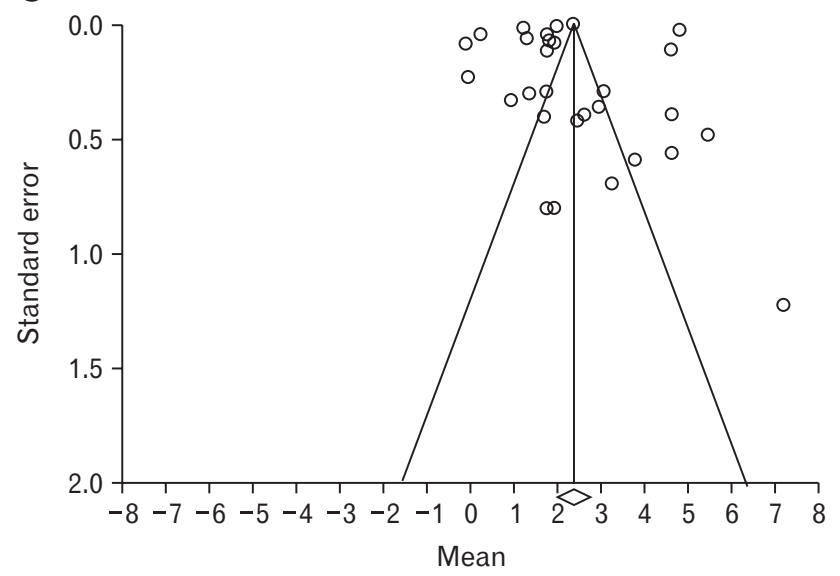

response rates for changes in bowel patterns (Table 2).

Of the articles included in the analysis, 16 focused on chronic constipation, ${ }^{11,24-26,32-42} 11$ enrolled patients with IBS-C, ${ }^{27,43-51}$ with one also including patients with mixed bowel patterns. ${ }^{48}$ One study did not differentiate IBS-C from constipation. ${ }^{52}$ Sample sizes varied between $7^{38}$ and $1348,^{25}$ exceeding 100 in 10 of the publications (Table 1). A study design using randomized allocation of 2 distinct

\section{B}

\section{Reference}

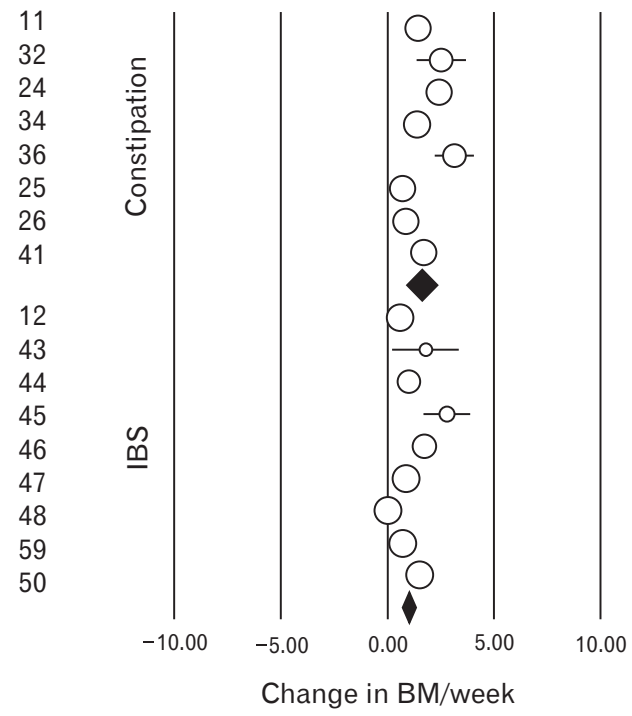

Figure 3. Forest plot showing treatment-induced increases in bowel frequency for active interventions (A) or placebo groups (B). (C) Shows the funnel plot for changes in bowel frequencies. IBS, irritable bowel syndrome; BM, bowel movement. 
groups to either an active or control intervention was used in 19 of the trials. The remaining seven publications described trials using a cross-over design $^{32,40}$ or were unblinded cohort studies. ${ }^{35,37-39,51}$ Five trials compared two active agents with each other, ${ }^{27,33,35,42,52,53}$ with the other trials using placebos as controls (Table 1). Most trials relied on medical, herbal, or dietary interventions, with only one trial describing the effect of biofeedback ${ }^{35}$ and 2 studies reporting the effect of subtotal colectomy ${ }^{39}$ or sacral nerve stimulation, ${ }^{37}$ respectively.

\section{Bowel Movement Frequency}

As expected from a target population of constipated patients enrolled in the published trials, baseline bowel movement (BM) frequencies were low, with a mean weekly BM frequency of 2.35 [2.07-2.64] (Fig. 2A). The detailed definition of BM endpoints significantly affected the numeric results. Studies reporting simple mean weekly BMs demonstrated greater frequencies (2.87 [2.563.19]) compared with weekly spontaneous BM frequency (1.92 [1.31-2.53]) or "complete spontaneous" BM frequency (1.06 [0.54-1.58]; comparison between endpoints: $\mathrm{Q}=35.9, P<0.001$; Fig. 2B). While the funnel plot did not suggest systematic skewing of results (Fig. 2C), the intercept of Egger's regression indicated potential publication bias (intercept: 10.55 (SEM: 1.51; $P<$ $0.001)$.

Interventions increased weekly BM frequency in all cohorts by 2.17 [1.88-2.47] (Fig. 3A). Within the group of controlled studies using parallel designs, active interventions were superior to placebo (differences in means: 0.43 [0.36-0.49]), with less of a difference observed in cohorts treated for constipation (0.36 [0.29-0.43]) compared to those with IBS-C $(0.56[0.45-0.66] ; \mathrm{Q}=9.0 ; P=$ 0.009; Fig. 3B). An assessment for potential bias in reporting treatment effects did not show significant skewing of results with Eggert's regression intercept being 2.61 (SEM: $3.65 ; P=0.247$ ).

\section{Pain Intensity Ratings}

Baseline pain levels were in the moderate range, with an intensity rating of 2.12 [1.81-2.42] based on a 5-point rating scale (Fig. $4 \mathrm{~A}$ ). While the funnel plot did not demonstrate asymmetry (Fig. 4B), the intercept of Egger's regression suggested publication bias (10.46 (SEM: 1.98), $P<0.001)$. Treatments reduced pain ratings in patients with chronic constipation and IBS-C by 0.58 [0.49-0.68] points (Fig. 5A and 5B). Only 2 treatments (one with colchicine, the other with tegaserod) were associated with increased pain ratings in 2 small studies. ${ }^{27,40}$ One additional study reported slightly higher rates of discomfort in a placebo-treated cohort. ${ }^{48}$ When we limited the comparisons to controlled trials with parallel designs, we found that active interventions were superior to placebos (difference of 0.26 [0.20-0.32]), with significantly lower pain reductions observed in cohorts with constipation $(0.14$ [0.07-0.21]) compared with IBS-C (0.53 [0.43-0.64]; $\mathrm{Q}=39.2 ; P=0.001)$. Figure 5C demonstrates that these studies did not show obvious skewing, even

A

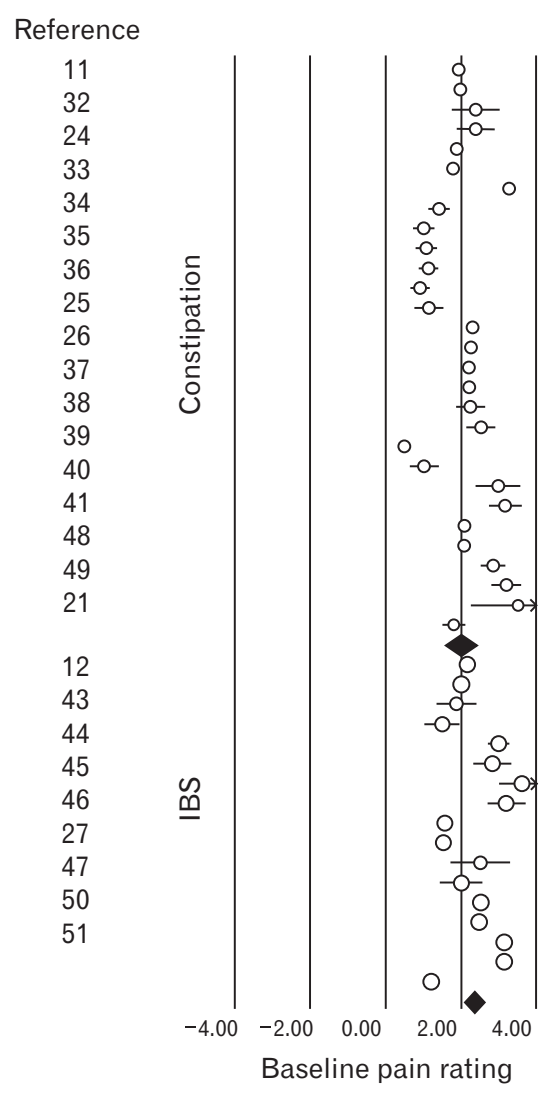

B

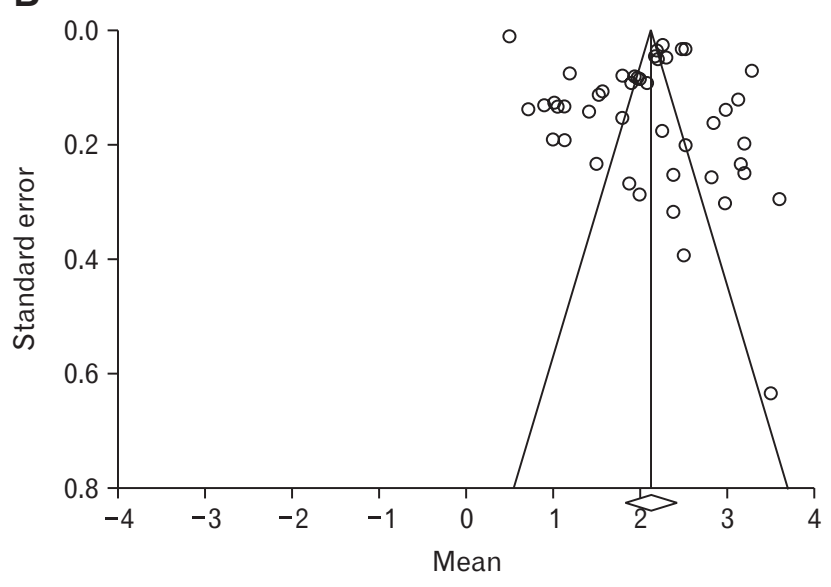

Figure 4. Forest plot baseline pain ratings (A) with grouping based on constipation or irritable bowel syndrome (IBS) with constipation. (B) Shows the funnel plot for baseline pain ratings. 
though the intercept of Egger's regression with -2.15 (SEM: 1.07; $P=0.025)$ indicated publication bias.

\section{Comparison Between Trials in Cohorts with Constipation and Irritable Bowel Syndrome with Constipation}

Cohorts with chronic constipation (2.00 [1.62-2.38]) had a lower baseline weekly defecation frequency than those with IBS-C

A

Reference
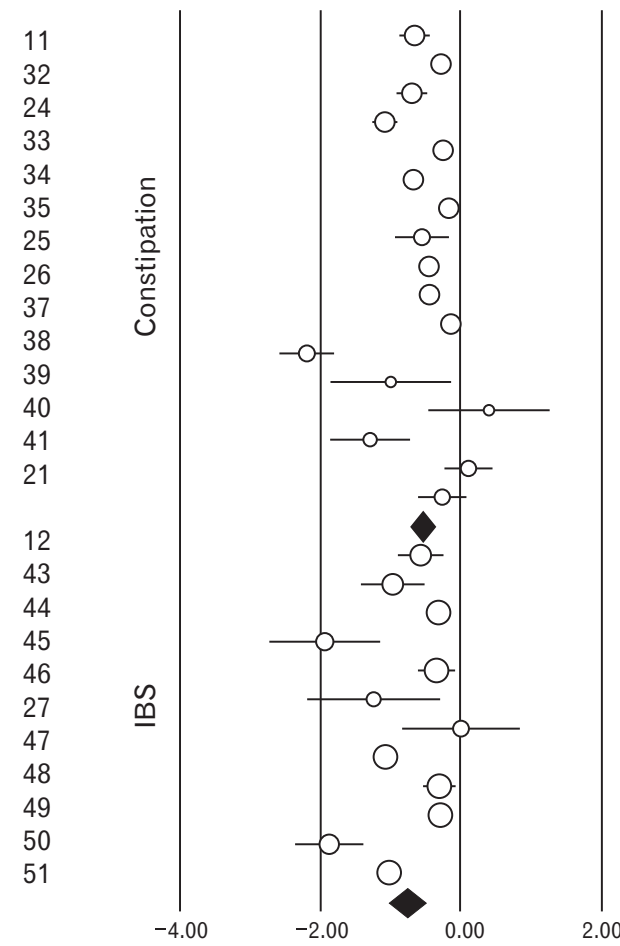

Change in pain rating

C

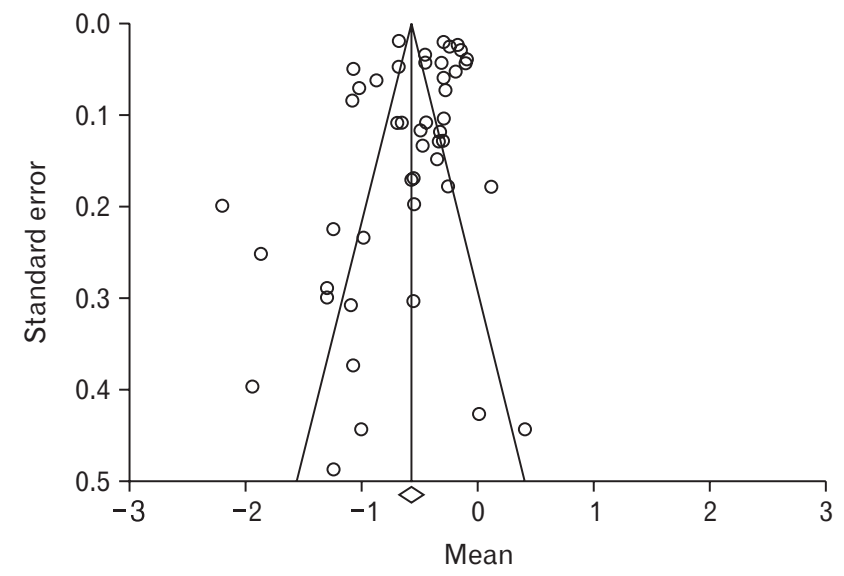

(2.77 [2.40-3.14]; $\mathrm{Q}=8.18, P=0.002)$. Treatment effects expressed in increases in weekly bowel frequency differed significantly differences between cohorts with constipation (active treatment: 3.49 [2.79-4.20]; placebo: 1.73 [1.02-2.43]) and IBS-C (active intervention: 1.74 [1.13-2.35]; placebo: 1.01 [0.72-1.31]; $\mathrm{Q}=13.5, P$ $<0.001)$. Cohorts with IBS-C patients tended to describe slightly higher baseline pain ratings (2.35 [2.10-2.60]) than those with constipation (2.02 [1.63-2.42]), but this difference was not statistically

\section{B}

\section{Reference}
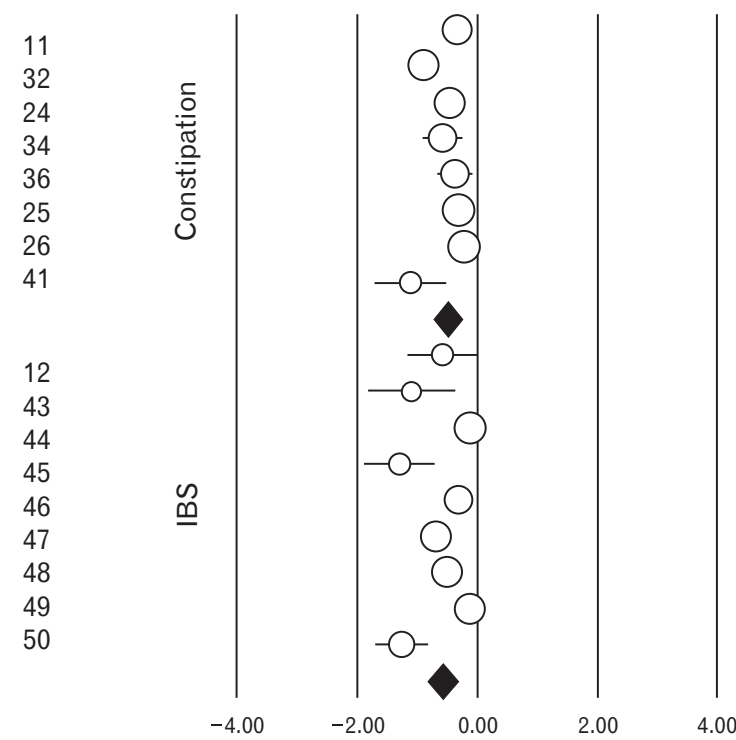

Change in pain rating

Figure 5. Forest plot showing treatment-induced decreases in pain ratings for active interventions (A) or placebo groups (B), with grouping based on constipation or irritable bowel syndrome (IBS) with constipation. (C) Shows the funnel plot for changes in bowel frequencies. 
significant $(\mathrm{Q}=1.91 ; P=0.167)$. Therapies led to comparable decreases in pain ratings in studies focusing on constipation $(0.53$ [0.41-0.65]; active treatment: 0.70 [0.40-0.55]; placebo: 0.49 [0.26-0.71]) and IBS-C (0.68 [0.51-0.84]; $\mathrm{Q}=2.0, P=0.158$; active treatment: 0.77 [0.52-1.03]; placebo: 0.56 [0.32-0.81]).

\section{Relationship Between Bowel Movement Frequency and Abdominal Pain}

We hypothesized that laxation would improve abdominal pain in those with chronic constipation and IBS-C independent of the mechanism of the laxative agent. To test this hypothesis, we used meta-regression techniques applied to the aggregate data on baseline and post-treatment assessments of weekly BM frequency and abdominal pain, which showed that increases in weekly BM frequency were significantly correlated with improvements in pain scores $(\mathrm{Q}=13.8, P<0.001$; Fig. 6). These data were taken from studies using multiple different therapeutic strategies, including conventional laxatives; in addition, the distribution of data obtained in these studies does show distinct clustering of tegaserod, lubiprostone and linaclotide, agents with presumably specific advantages due to their effects of abdominal discomfort. Thus, this analysis supports the underlying hypothesis that improvement in abdominal pain often accompanies laxation. Considering the potential skewing of data through prospectively designed cohort studies without random design, we repeated the analysis after excluding these studies. Results remained unchanged with meta-regression showing a significant correlation between changes bowel frequency and pain relief (Supplementary Figure).

\section{Analysis of Studies with Dichotomous Endpoints}

For our secondary analysis, we reviewed studies with dichotomous endpoints that provided enough information to allow for meta-regression analysis. Thirteen publications ( 9 constipation, 4 IBS-C) defined response rates based on changes in bowel patterns or global relief of symptoms for IBS-C, and provided information about associated changes in pain intensity (Table 2). We entered
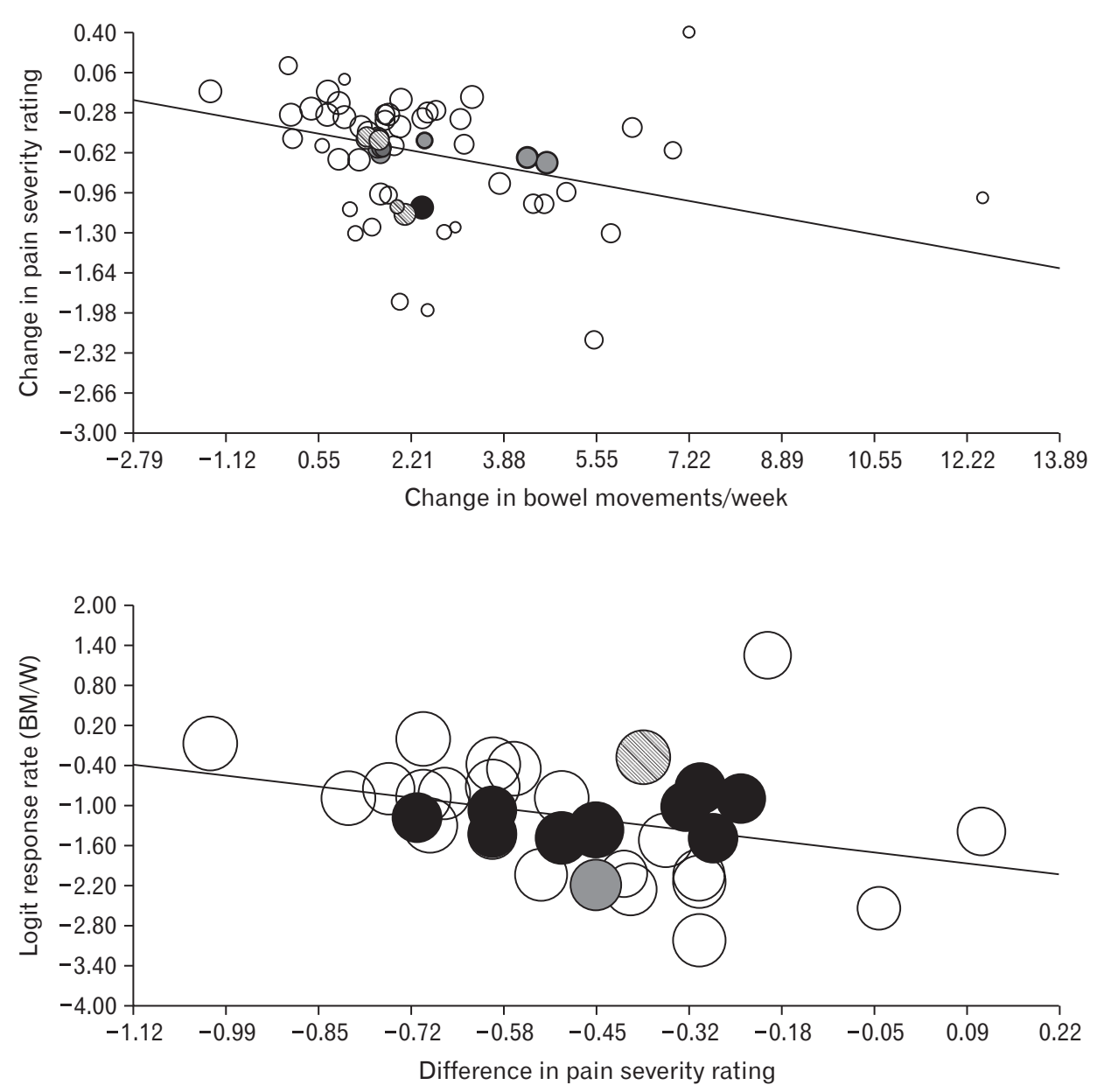

Figure 6. Meta-regression showing the correlation between changes in bowel frequency and pain ratings. Study arms using agents with presumably relevant benefit on pain ratings are marked specifically (linaclotide: black; lubiprostone: grey; tegaserod: hatched). Symbol size is proportional to the relative weight in the analysis.

Figure 7. Meta-analysis of studies with dichotomizing assessment of treatment effects demonstrating the correlation between changes in pain rating and response rates based on change in bowel patterns. Study arms using agents with presumably relevant benefit on pain ratings are marked specifically (linaclotide: black; lubiprostone: grey; tegaserod: hatched). Symbol size is proportional to the relative weight in the analysis. $\mathrm{BM} / \mathrm{W}$, bowel movements per week. 
reported data for each subgroup within a trial and found similar response rates for studies of constipation (active intervention: 30.1\% [24.6-36.1]; placebo: 11.7\% [7.4-18.0]) and IBS-C (active interventions: $27.2 \%$ [16.2-41.9], $\mathrm{Q}=0.29, P=0.591$; placebo: 23.5\% [13.5-27.6]; $\mathrm{Q}=3.8 ; P=0.051)$. Aggregate response rates as defined by increased BM frequency significantly correlated with changes in pain ratings in the meta-regression analysis (Q-6.32; $P<0.05$; Fig. 7), consistent with our hypothesized relationship between increased BM frequency and reductions in abdominal pain.

\section{Discussion}

Considering the recent emphasis on pain relief as a specific benefit of linaclotide's mechanism of action, ${ }^{10,21,54}$ we sought to determine whether there is a general relationship between improvements in bowel frequency and decreases in abdominal pain in patients with constipation or IBS-C. Our systematic analysis of controlled and cohort studies confirms that effective laxation correlates with improved pain ratings in patients with constipation or IBS-C, an effect that is not limited to a small number of agents with a specific mechanism. The meta-regression analysis demonstrates a correlation between the increase in weekly BM frequency and reductions in abdominal pain, which does not only support the role of constipation as a contributor to abdominal discomfort, but also suggests that specific visceral analgesic properties are not needed to improve discomfort associated with constipation.

Based largely on their impact on abdominal pain, the recently introduced pro-secretory agents (lubiprostone and linaclotide) were approved in the United States not only for the treatment of chronic constipation, but also specifically for the management of IBS-C, with marketing campaigns emphasizing their presumably unique benefits related to pain relief. ${ }^{16-18}$ In the case of linaclotide, preclinical mechanistic studies supported the clinical data and suggested a possible specific analgesic effect. These investigations, which were previously also conducted with tegaserod, assessed acute responses to colorectal distension or stretch in normal subjects or animals. ${ }^{19-21}$ Similar experiments did not reveal effects on sensory function with lubiprostone. ${ }^{22}$ Despite the different impact on colorectal sensatory mechanisms, ${ }^{19,21-23}$ linaclotide, lubiprostone and tegaserod similarly alleviated chronic pain ratings in IBS-C and constipation. ${ }^{9-11,24-26}$

The relationship between improved bowel patterns and decreased discomfort, as highlighted by our meta-analysis, does not establish an underlying mechanism, but fits into a larger context of past experimental and clinical data. As mentioned above, loperamide reduced bowel frequency in healthy volunteers to a degree sufficient to trigger symptoms consistent with IBS-C. ${ }^{29}$ While few comparative effectiveness analyses of active agents are available, the limited evidence does not support superiority of more recently developed agents with polyethylene glycol (PEG) being either superior or equivalent to tegaserod. ${ }^{27,28}$ Similar results were reported for prucalopride, which also targets serotonin receptors. This agent provided no more relief than did PEG at the primary endpoint, and was even inferior at almost all secondary endpoints in a trial of patients with chronic constipation. ${ }^{55}$ This trial was not entered into our analysis, as insufficient quantitative data were provided for baseline pain levels. Finally, a similarly designed clinical trial in children suffering from chronic constipation also demonstrated that the active control (PEG) was more effective than prucalopride. ${ }^{56}$

Our results do not only raise questions about proposed mechanisms of symptom relief in IBS-C, they also have potential implications for trial design. As there is no firmly established standard of care in constipation or IBS-C, placebo-controlled trials are justifiable. However, recently published guidelines summarized the available evidence and identified strong support for the use of polyethylene glycol or lactulose as effective treatment of chronic constipation. ${ }^{57}$ Both agents are approved and available in the United States and most other countries, come with a substantially lower price tag than the more recently introduced medications, and could thus function as an accepted reference therapy as done in some of the trials involving prucalopride and tegaserod. ${ }^{27,28,55}$ While not a typical concern in the design of clinical trials, we mentioned drug prices in this context, as the initiation of tegaserod therapy increased overall outpatient costs by more than $30 \%$, raising the fraction of medication-related expenses from $39 \%$ to $68 \%{ }^{58}$ Facing such cost concerns, modeling studies for this and other agents concluded that the increased expenses were offset by an improved quality of life and less frequent work absenteeism. ${ }^{59-61}$ However, these conclusions were based upon trials without active intervention in the control group, which is unlikely to occur in clinical practice. Our results and the previously mentioned comparative trials question the validity of these models, as cheaper and effective interventions are available, and as patients seeking medical attention for symptoms of constipation will typically initiate some form of active treatment.

We focused on publications that provided sufficient quantitative details about endpoints for two distinct time points separated by an intervention. Essentially, all studies of prucalopride and several trials using lubiprostone or linaclotide dichotomized responses, or relied on more global ratings of bowel patterns, and were thus not included in our primary analysis. However, an assessment of a subset of these studies that defined treatment response rates based 
on changes in bowel frequency still showed a similar correlation response rates based on changes in bowel pattern and decreases in abdominal pain ratings. Interestingly, the correlation between aggregate measures of published studies addressing bowel patterns and pain correspond with results of a pilot study, which demonstrated a significant relationship between changes in bowel frequency and pain ratings for individual patients receiving linaclotide for constipation. ${ }^{62}$ The described correlation between improved pain ratings were not only reported in studies of the newly introduced agents for IBS-C, ${ }^{63-67}$ but were also observed in many other trials, which did not meet inclusion criteria for this analysis and examined the effects of interventions ranging from fiber supplements, ${ }^{68,69}$ to herbal preparations, ${ }^{70}$ biofeedback, ${ }^{71}$ bisacodyl, ${ }^{72}$ or osmotic laxatives. ${ }^{73-75}$

While not the focus of this analysis, we noted some statistically significant, but clinically minor, differences in the endpoints between patient cohorts with constipation and IBS-C. Moderate pain levels and low stool frequencies characterized both disorders. Studies typically relied on accepted consensus criteria for functional gastrointestinal disorders when defining their target population. The researchers often included authors who participated in the formulation of these very criteria and/or led trials examining drug effects on constipation or IBS-C in separate studies with similar methodology, at times operationally defining IBS-C by a pain intensity of 3 or more on a 5 -point scale. ${ }^{24,25,63,76-78}$ We recognize that other factors, such as pain frequency or impact on quality of life, were not measured and may define differences in those with constipation compared to IBS-C. While our meta-analysis cannot truly address conceptual issues about disease mechanisms or manifestations, the findings are consistent with prospective cohort studies that show a substantial overlap between constipation and IBS-C. ${ }^{1,3,4}$ Prospective studies will have to determine whether and to what degree these diseases are truly distinct or whether they primarily differ based on a potentially shifting focus and emphasis on symptoms associated with constipation.

Despite our relatively stringent inclusion criteria, the detailed definitions and assessments of endpoints differed among the studies entered into our analysis. Most importantly, the predefined assessment of bowel patterns as a simple, spontaneous, or complete spontaneous BM frequency significantly affected results related to defecation. In addition, effects of interventions were assessed over a wide range of time periods, ranging from 4 weeks to more than 12 months. Differences in trial design, recruitment strategies, sex distribution, ethnic background, and interventions further add to the variability. Overall changes in pain intensity ratings were around $25 \%$, which raises questions about the true relevance of changes observed. Prior studies concluded that decreases in pain severity by about $30 \%$ are indeed clinically meaningful. ${ }^{79}$ Considering the role of pain in defining overall improvement and the reported response rates of about $30 \%$, responders likely experienced more significant relief than indicated by the averaged results. Finally, we did not restrict our assessment to controlled trials and included small cohort studies, which described skewed patient populations with more severe disease that were selected for surgical therapy. However, results remained significant even when these cohorts were excluded (Supplementary Figure).

In conclusion, our systematic analysis confirms that effective treatment of constipation also improves pain and discomfort without the need for specific visceral analgesic properties. Considering the substantial concerns about healthcare costs and the long term financial impact of medical therapies for chronic conditions, comparative effectiveness analyses and appropriately designed assessments of the indirect economic impact are needed to truly define the potential advantage of newer and more costly treatments for patients with chronic constipation and IBS-C.

\section{Supplementary Materials}

Note: To access the supplementary figure mentioned in this article, visit the online version of Journal of Neurogastroenterology and Motility at http://www.jnmjournal.org/, and at http://dx.doi. org/10.5056/jnm15171.

\section{Financial support: None.}

\section{Conflicts of interest: None.}

Author contributions: Klaus Bielefeldt designed the study, reviewed articles, completed the analysis, and wrote the manuscript; David J Levinthal reviewed articles, edited and approved the manuscript; and Salman Nusrat independently reviewed articles, participated in the analysis, and corrected and approved the manuscript.

\section{References}

1. Ford AC, Bercik P, Morgan DG, Bolino C, Pintos-Sanchez MI, Moayyedi P. Characteristics of functional bowel disorder patients: a crosssectional survey using the Rome III criteria. Aliment Pharmacol Ther 2014;39:312-321.

2. Longstreth GF, Thompson WG, Chey WD, Houghton LA, Mearin F, Spiller RC. Functional bowel disorders. Gastroenterology 2006;130: 
1480-1491.

3. Wong RK, Palsson OS, Turner MJ, et al. Inability of the Rome III criteria to distinguish functional constipation from constipation-subtype irritable bowel syndrome. Am J Gastroenterol 2010;105:2228-2234.

4. Shekhar C, Monaghan PJ, Morris J, et al. Rome III functional constipation and irritable bowel syndrome with constipation are similar disorders within a spectrum of sensitization, regulated by serotonin. Gastroenterology 2013;145:749-757.

5. Wysowski DK, Corken A, Gallo-Torres H, Talarico L, Rodriguez EM. Postmarketing reports of QT prolongation and ventricular arrhythmia in association with cisapride and food and drug administration regulatory actions. Am J Gastroenterol 2001;96:1698-1703.

6. Lisi DM. LOtronex withdrawal. Arch Intern Med 2002;162:101.

7. Pasricha PJ. Desperately seeking serotonin... A commentary on the withdrawal of tegaserod and the state of drug development for functional and motility disorders. Gastroenterology 2007;132:2287-2290.

8. FDA. Guidance for industry: irritable bowlel syndrome - clinical evaluation of drugs for treatment. Available from URL: http://www.fda.gov/ downloads/Drugs/Guidances/UCM205269.pdf (accessed 14 December 2015).

9. Lembo AJ, Kurtz CB, MacDougall JE, et al. Efficacy of linaclotide for patients with chronic constipation. Gastroenterology 2010;138:886-895, e1.

10. Johnston JM, Kurtz CB, MacDougall JE, et al. Linaclotide improves abdominal pain and bowel habits in a phase IIb study of patients with irritable bowel syndrome with constipation. Gastroenterology 2010;139:1877-1886, e2.

11. Johanson JF, Morton D, Geenen J, Ueno R. Multicenter, 4-week, double-blind, randomized, placebo-controlled trial of lubiprostone, a locally-acting type-2 chloride channel activator, in patients with chronic constipation. Am J Gastroenterol 2008;103:170-177.

12. Johanson JF, Drossman DA, Panas R, Wahle A, Ueno R. Clinical trial: phase 2 study of lubiprostone for irritable bowel syndrome with constipation. Aliment Pharmacol Ther 2008;27:685-696.

13. Johanson JF, Ueno R. Lubiprostone, a locally acting chloride channel activator, in adult patients with chronic constipation: a double-blind, placebo-controlled, dose-ranging study to evaluate efficacy and safety. Aliment Pharmacol Ther 2007;25:1351-1361.

14. Bharucha AE, Linden DR. Linaclotide - a secretagogue and antihyperalgesic agent - what next? Neurogastroenterol Motil 2010;22:227-231.

15. Camilleri M. Novel medications for the irritable bowel syndrome: motility and sensation. J Pediatr Gastroenterol Nutr 2001;32(suppl 1):S35-S37.

16. Lang $\mathrm{L}$. The food and drug administration approves lubiprostone for irritable bowel syndrome with constipation. Gastroenterology 2008;135:7.

17. Horwitz B. FDA OK's two drugs for irritable bowel syndrome. The arsenal of IBS drugs is growing, but diagnosis is tricky. Health News 2002;8:1-2.

18. Vazquez-Roque MI, Bouras EP. Linaclotide, novel therapy for the treatment of chronic idiopathic constipation and constipation-predominant irritable bowel syndrome. Adv Ther 2013;30:203-211.

19. Coffin B, Farmachidi JP, Rueegg P, Bastie A, Bouhassira D. Tegaserod, a 5- $\mathrm{HT}_{4}$ receptor partial agonist, decreases sensitivity to rectal distension in healthy subjects. Aliment Pharmacol Ther 2003;17:577-585.
20. Hoffman JM, Tyler K, MacEachern SJ, et al. Activation of colonic mucosal $5-\mathrm{HT}_{4}$ receptors accelerates propulsive motility and inhibits visceral hypersensitivity. Gastroenterology 2012;142:844-854, e4.

21. Castro J, Harrington AM, Hughes PA, et al. Linaclotide inhibits colonic nociceptors and relieves abdominal pain via guanylate cyclase- $\mathrm{C}$ and extracellular cyclic guanosine 3',5'-monophosphate. Gastroenterology 2013;145:1334-1346, e1-e11.

22. Whitehead WE, Palsson OS, Gangarosa L, Turner M, Tucker J. Lubiprostone does not influence visceral pain thresholds in patients with irritable bowel syndrome. Neurogastroenterol Motil 2011;23:944-e400.

23. Sabaté JM, Bouhassira D, Poupardin C, Wagner A, Loria Y, Coffin B. Sensory signalling effects of tegaserod in patients with irritable bowel syndrome with constipation. Neurogastroenterol Motil 2008;20:134-141.

24. Barish CF, Drossman D, Johanson JF, Ueno R. Efficacy and safety of lubiprostone in patients with chronic constipation. Dig Dis Sci 2010;55: 1090-1097.

25. Johanson JF, Wald A, Tougas G, et al. Effect of tegaserod in chronic constipation: a randomized, double-blind, controlled trial. Clin Gastroenterol Hepatol 2004;2:796-805.

26. Kamm MA, Müller-Lissner S, Talley NJ, et al. Tegaserod for the treatment of chronic constipation: a randomized, double-blind, placebocontrolled multinational study. Am J Gastroenterol 2005;100:362-372.

27. Di Stefano M, Miceli E, Mazzocchi S, Tana P, Missanelli A, Corazza GR. Effect of tegaserod on recto-sigmoid tonic and phasic activity in constipation-predominant irritable bowel syndrome. Am J Gastroenterol 2007;102:1720-1726.

28. Di Palma JA, Cleveland MV, McGowan J, Herrera JL. A randomized, multicenter comparison of polyethylene glycol laxative and tegaserod in treatment of patients with chronic constipation. Am J Gastroenterol 2007;102:1964-1971.

29. Marcus SN, Heaton KW. Irritable bowel-type symptoms in spontaneous and induced constipation. Gut 1987;28:156-159.

30. Janssen P, Harris MS, Jones M, et al. The relation between symptom improvement and gastric emptying in the treatment of diabetic and idiopathic gastroparesis. Am J Gastroenterol 2013;108:1382-1391.

31. Thompson SG, Higgins JP. How should met-regression analyses be undertaken and interpreted? Stat Med 2002;21:1559-1573.

32. Badiali D, Corazziari E, Habib FI, et al. Effect of wheat bran in treatment of chronic nonorganic constipation. A double-blind controlled trial. Dig Dis Sci 1995;40:349-356.

33. Chaussade S, Minić M. Comparison of efficacy and safety of two doses of two different polyethylene glycol-based laxatives in the treatment of constipation. Aliment Pharmacol Ther 2003;17:165-172.

34. Cheng CW, Bian ZX, Zhu LX, Wu JC, Sung JJ. Efficacy of a Chinese herbal proprietary medicine (Hemp Seed Pill) for functional constipation. Am J Gastroenterol 2011;106:120-129.

35. Chiarioni G, Whitehead WE, Pezza V, Morelli A, Bassotti G. Biofeedback is superior to laxatives for normal transit constipation due to pelvic floor dyssynergia. Gastroenterology 2006;130:657-664.

36. Fateh R, Iravani S, Frootan M, Rasouli MR, Saadat S. Synbiotic preparation in men suffering from functional constipation: a randomised controlled trial. Swiss Med Wkly 2011;141:w13239. 
37. Kamm MA, Dudding TC, Melenhorst J, et al. Sacral nerve stimulation for intractable constipation. Gut 2010;59:333-340.

38. Verne GN, Eaker EY, Davis RH, Sninsky CA. Colchicine is an effective treatment for patients with chronic constipation: an open-label trial. Dig Dis Sci 1997;42:1959-1963.

39. Verne GN, Hocking MP, Davis RH, et al. Long-term response to subtotal colectomy in colonic inertia. J Gastrointest Surg 2002;6:738-744.

40. Verne GN, Davis RH, Robinson ME, Gordon JM, Eaker EY, Sninksy CA. Treatment of chronic constipation with colchicine: randomized, double-blind, placebo-controlled, crossover trial. Am J Gastroenterol 2003;98:1112-1116.

41. Ziegenhagen DJ, Kruis W. Cisapride treatment of constipation-predominant irritable bowel syndrome is not superior to placebo. J Gastroenterol Hepatol 2004;19:744-749.

42. Mansour NM, Ghaith O, El-Halabi M, Sharara AI. A prospective randomized trial of mosapride vs. placebo in constipation-predominant irritable bowel syndrome. Am J Gastroenterol 2012;107:792-793.

43. Min YW, Park SU, Jang YS, et al. Effect of composite yogurt enriched with acacia fiber and Bifidobacterium lactis. World J Gastroenterol 2012; 7:4563-4569.

44. Agrawal A, Houghton LA, Morris J, et al. Clinical trial: the effects of a fermented milk product containing Bifidobacterium lactis DN-173 010 on abdominal distension and gastrointestinal transit in irritable bowel syndrome with constipation. Aliment Pharmacol Ther 2009;29:104-114.

45. Awad RA, Camacho S. A randomized, double-blind, placebo-controlled trial of polyethylene glycol effects on fasting and postprandial rectal sensitivity and symptoms in hypersensitive constipation-predominant irritable bowel syndrome. Colorectal Dis 2010;12:1131-1138.

46. Chapman RW, Stanghellini V, Geraint M, Halphen M. Randomized clinical trial: macrogol/PEG 3350 plus electrolytes for treatment of patients with constipation associated with irritable bowel syndrome. Am J Gastroenterol 2013;108:1508-1515.

47. Rao S, Lembo AJ, Shiff SJ, et al. A 12-week, randomized, controlled trial with a 4-week randomized withdrawal period to evaluate the efficacy and safety of linaclotide in irritable bowel syndrome with constipation. Am J Gastroenterol 2012;107:1714-1724.

48. Roberts LM, McCahon D, Holder R, Wilson S, Hobbs FD. A randomised controlled trial of a probiotic 'functional food' in the management of irritable bowel syndrome. BMC Gastroenterol 2013;13:45.

49. Sallon S, Ben-Arye E, Davidson R, Shapiro H, Ginsberg G, Ligumsky M. A novel treatment for constipation-predominant irritable bowel syndrome using Padma Lax, a Tibetan herbal formula. Digestion 2002;65:161-171.

50. Van Outryve M, Milo R, Toussaint J, Van Eeghem P. "Prokinetic" treatment of constipation-predominant irritable bowel syndrome: a placebocontrolled study of cisapride. J Clin Gastroenterol 1991;13:49-57.

51. Layer P, Keller J, Mueller-Lissner S, Rüegg P, Loeffler H. Tegaserod: long-term treatment for irritable bowel syndrome patients with constipation in primary care. Digestion 2005;71:238-244.

52. Medoff J, Katz S, Malik P, et al. Open-label, dose-ranging pilot study of 4 weeks of low-dose therapy with sodium phosphate tablets in chronically constipated adults. Clin Ther 2004;26:1479-1491.
53. Ueno N, Inui A, Satoh Y. The effect of mosapride citrate on constipation in patients with diabetes. Diabetes Res Clin Pract 2010;87:27-32.

54. Layer P, Stanghellini V. Review article: linaclotide for the management of irritable bowel syndrome with constipation. Aliment Pharmacol Ther 2014;39:371-384.

55. Cinca R, Chera D, Gruss HJ, Halphen M. Randomised clinical trial: macrogol/PEG 3350+electrolytes versus prucalopride in the treatment of chronic constipation - a comparison in a controlled environment. Aliment Pharmacol Ther 2013;37:876-886.

56. Mugie SM, Korczowski B, Bodi P, et al. Prucalopride is no more effective than placebo for children with functional constipation. Gastroenterology 2014;147:1285-1295, e1.

57. Ford AC, Moayyedi P, Lacy BE, et al. American College of Gastroenterology monograph on the management of irritable bowel syndrome and chronic idiopathic constipation. Am J Gastroenterol 2014;109(suppl 1): S2-S26.

58. Bloom MA, Barghout V, Kahler KH, et al. Budget impact of tegaserod on a managed care organization formulary. Am J Manag Care 2005;11: S27-S34.

59. Bracco A, Jönsson B, Ricci JF, Drummond M, Nyhlin H. Economic evaluation of tegaserod vs. placebo in the treatment of patients with irritable bowel syndrome: an analysis of the TENOR study. Value Health 2007;10:238-246.

60. Smith DG, Barghout V, Kahler KH. Tegaserod treatment for IBS: a model of indirect costs. Am J Manag Care 2005;11:S43-S50.

61. Huang H, Taylor DC, Carson RT, et al. Economic evaluation of linaclotide for the treatment of adult patients with irritable bowel syndrome with constipation in the United States. J Med Econ 2015;18:283-294.

62. Johnston JM, Kurtz CB, Drossman DA, et al. Pilot study on the effect of linaclotide in patients with chronic constipation. Am J Gastroenterol 2009;104:125-132.

63. Camilleri M, Kerstens R, Rykx A, Vandeplassche L. A placebocontrolled trial of prucalopride for severe chronic constipation. N Engl J Med 2008;358:2344-2354.

64. Tack J, van Outryve M, Beyens G, Kerstens R, Vandeplassche L. Prucalopride (Resolor) in the treatment of severe chronic constipation in patients dissatisfied with laxatives. Gut 2009;58:357-365.

65. Quigley EM, Vandeplassche L, Kerstens R, Ausma J. Clinical trial: the efficacy, impact on quality of life, and safety and tolerability of prucalopride in severe chronic constipation - a 12-week, randomized, doubleblind, placebo-controlled study. Aliment Pharmacol Ther 2009;29:315328.

66. Quigley EM, Tack J, Chey WD, et al. Randomised clinical trials: linaclotide phase 3 studies in IBS-C - a prespecified further analysis based on European Medicines Agency-specified endpoints. Aliment Pharmacol Ther 2013;37:49-61.

67. Chey WD, Lembo AJ, Lavins BJ, et al. Linaclotide for irritable bowel syndrome with constipation: a 26-week, randomized, double-blind, placebo-controlled trial to evaluate efficacy and safety. Am J Gastroenterol 2012;107:1702-1712.

68. Prior A, Whorwell PJ. Double blind study of ispaghula in irritable bowel syndrome. Gut 1987;28:1510-1513. 
69. Kumar A, Kumar N, Vij JC, Sarin SK, Anand BS. Optimum dosage of ispaghula husk in patients with irritable bowel syndrome: correlation of symptom relief with whole gut transit time and stool weight. Gut 1987;28:150-155.

70. Odes HS, Madar Z. A double-blind trial of a celandin, aloevera and psyllium laxative preparation in adult patients with constipation. Digestion 1991;49:65-71.

71. Koutsomanis D, Lennard-Jones JE, Roy AJ, Kamm MA. Controlled randomised trial of visual biofeedback versus muscle training without a visual display for intractable constipation. Gut 1995;37:95-99.

72. Kamm MA, Mueller-Lissner S, Wald A, Richter E, Swallow R, Gessner $\mathrm{U}$. Oral Bisacodyl is effective and well-tolerated in patients with chronic constipation.Clin Gastroenterol Hepatol 2011;9:577-583.

73. Bouhnik Y, Neut C, Raskine L, et al. Prospective, randomized, parallelgroup trial to evaluate the effects of lactulose and polyethylene glycol-4000 on colonic flora in chronic idiopathic constipation. Aliment Pharmacol Ther 2004;19:889-899.

74. Mueller-Lissner S, Kamm MA, Wald A, et al. Multicenter, 4-week, double-blind, randomized, placebo-controlled trial of sodium picosulfate in patients with chronic constipation. Am J Gastroenterol 2010;105:897903.

75. Dupont C, Campagne A, Constant F. Efficacy and safety of a magnesium sulfate-rich natural mineral water for patients with functional constipation. Clin Gastroenterol Hepatol 2014;12:1280-1287.

76. Heymen S, Scarlett Y, Jones K, Ringel Y, Drossman D, Whitehead WE. Randomized, controlled trial shows biofeedback to be superior to alternative treatments for patients with pelvic floor dyssynergia-type constipation. Dis Colon Rectum 2007;50:428-441.
77. Drossman DA, Chey WD, Johanson JF, et al. Clinical trial: lubiprostone in patients with constipation-associated irritable bowel syndrome--results of two randomized, placebo-controlled studies. Aliment Pharmacol Ther 2009;29:329-341.

78. Saad R, Chey WD. Tegaserod in the treatment of irritable bowel syndrome with constipation. Womens Health 2006;2:29-42.

79. Macdougall JE, Johnston JM, Lavins BJ, et al. An evaluation of the FDA responder endpoint for IBS-C clinical trials: analysis of data from linaclotide Phase 3 clinical trials. Neurogastroenterol Motil 2013;25:481486.

80. Lembo AJ, Schneier HA, Shiff SJ, et al. Two randomized trials of linaclotide for chronic constipation. N Engl J Med 2011;365:527-536.

81. Ke M, Zou D, Yuan Y, et al. Prucalopride in the treatment of chronic constipation in patients from the Asia-Pacific region: a randomized, double-blind, placebo-controlled study. Neurogastroenterol Motil 2012;24:999-e541.

82. Fried M, Johanson JF, Gwee KA, Wagner A, Pecher E, Rueegg P. Efficacy of tegaserod in chronic constipation in men. Am J Gastroenterol 2007;102:362-370.

83. Corazziari E, Badiali D, Bazzocchi G, et al. Long term efficacy, safety, and tolerabilitity of low daily doses of isosmotic polyethylene glycol electrolyte balanced solution (PMF-100) in the treatment of functional chronic constipation. Gut 2000;46:522-526.

84. Novick J, Miner P, Krause R, et al. A randomized, double-blind, placebo-controlled trial of tegaserod in female patients suffering from irritable bowel syndrome with constipation. Aliment Pharmacol Ther 2002;16: 1877-1888. 